\title{
Paleosols can promote root growth of recent vegetation - a case study from the sandy soil-sediment sequence Rakt, the Netherlands
}

\author{
Martina I. Gocke ${ }^{1,2}$, Fabian Kessler ${ }^{1}$, Jan M. van Mourik ${ }^{3}$, Boris Jansen ${ }^{4}$, and Guido L. B. Wiesenberg ${ }^{1}$ \\ ${ }^{1}$ Department of Geography, University of Zurich, Winterthurerstr. 190, 8057 Zurich, Switzerland \\ ${ }^{2}$ Institute of Crop Science and Resource Conservation, University of Bonn, Nussallee 13, \\ 53115 Bonn, Germany \\ ${ }^{3}$ IBED-Paleoecology, University of Amsterdam, P.O. Box 94240, Amsterdam 1090 GE, the Netherlands \\ ${ }^{4}$ IBED-Earth Surface Science, University of Amsterdam, P.O. Box 94240, \\ Amsterdam 1090 GE, the Netherlands \\ Correspondence to: Martina I. Gocke (mgocke@uni-bonn.de)
}

Received: 3 November 2015 - Published in SOIL Discuss.: 14 December 2015

Accepted: 15 September 2016 - Published: 21 October 2016

\begin{abstract}
Soil studies commonly comprise the uppermost meter for tracing, e.g., soil development. However, the maximum rooting depth of various plants significantly exceeds this depth. We hypothesized that deeper parts of the soil, soil parent material and especially paleosols provide beneficial conditions in terms of, e.g., nutrient contents, thus supporting their utilization and exploitation by deep roots. We aimed to decipher the different phases of soil formation in Dutch drift sands and cover sands. The study site is located at Bedafse Bergen (southeastern Netherlands) in a 200-year-old oak stand. A recent Podzol developed on drift sand covering a Plaggic Anthrosol that was piled up on a relict Podzol on Late Glacial eolian cover sand. Root-free soil and sediment samples, collected in $10-15 \mathrm{~cm}$ depth increments, were subjected to a multi-proxy physical and geochemical approach. The Plaggic Anthrosol revealed low bulk density and high phosphorous and organic carbon contents, whereas the relict Podzol was characterized by high iron and aluminum contents. Frequencies of fine (diameter $\leq 2 \mathrm{~mm})$ and medium roots $(2-5 \mathrm{~mm})$ were determined on horizontal levels and the profile wall for a detailed pseudo-three-dimensional insight. On horizontal levels, living roots were most abundant in the uppermost part of the relict Podzol with ca. 4450 and $220 \mathrm{~m}^{-2}$, significantly exceeding topsoil root abundances. Roots of oak trees thus benefited from the favorable growth conditions in the nutrient-rich Plaggic Anthrosol, whereas increased compactness and high aluminum contents of the relict Podzol caused a strong decrease of roots. The approach demonstrated the benefit of comprehensive root investigation to support interpretation of soil profiles, as fine roots can be significantly underestimated when quantified at the profile wall. The possible rooting of soil parent material and paleosols long after their burial confirmed recent studies on the potential influence of rooting to overprint sediment-(paleo)soil sequences of various ages, sedimentary and climatic settings. Potential consequences of deep rooting for terrestrial deep carbon stocks, located to a relevant part in paleosols, remain largely unknown and require further investigation.
\end{abstract}




\section{Introduction}

Paleosols that developed in Late Glacial eolian sediments like, e.g., loess, dune sands or cover sands are valuable archives to reconstruct paleovegetation, soil and land use history (e.g., Pye and Sherwin, 1999; Van Mourik et al., 2012; Wallinga et al., 2013), with the prerequisite that individual phases of soil formation and sedimentation are distinguishable from each other. Traditionally, pedogenic processes are assumed to impact the uppermost tens of centimeters of soil, as visible, e.g., from soil models and soil classification systems commonly comprising at maximum the uppermost meter (Schmidt et al., 2011; IUSS Working Group WRB, 2014). Although topsoils commonly show the highest root biomass and high concentrations of soil organic carbon (SOC) and most nutrients (Jobággy and Jackson, 2000, 2001), plants are able to generate deep roots which may penetrate also deeper parts of soil and underlying soil parent material until several meters (Canadell et al., 1996), depending on plant type and environmental conditions. This demonstrates the important role of the deep subsurface as a part of terrestrial ecosystems (Richter and Markewitz, 1995). Root penetration may thus also affect paleosols as recently discussed (Wiesenberg et al., 2015).

Gocke et al. (2014a) showed that ancient calcified roots of Holocene age were present throughout a European Late Pleistocene loess-paleosol sequence, penetrating several paleosols. This was recently confirmed by other sequences in southeastern Europe and China (Újvári et al., 2014; Li et al., 2015). Also living roots that were not connected to the vegetation on top of the profile were found at $9 \mathrm{~m}$ depth due to the slope position of the profile. Roots appeared despite comparatively low contents of most nutritional elements in the loess deposits (Gocke et al., 2014a). Both living and ancient roots were present preferentially in paleosols, which leads to the question of how unique or common this phenomenon is, and whether it applies, e.g., also to young (i.e., Holocene) soils with considerably higher nutrient stocks compared to Pleistocene sediments and paleosols. One example of young paleosols widely distributed in Central Europe are Plaggic Anthrosols. Plaggic agriculture was a historical form of agricultural land use which was applied on nutrient-poor sandy soils in northwestern Germany, the Netherlands and northeastern Belgium, amongst others, during the Middle Ages until the introduction of industrial fertilizers (Blume and Leinweber, 2004). Besides straw, additional stable fillings like fermented forest litter, grass and heath sods, obtained from the nearby landscape, were brought into stables (Van Mourik and Jansen, 2016). After enrichment with animal excrements the plaggic manure was brought back on the field, often together with compost (Giani et al., 2014). Driessen and Dudal (1991) stated that several properties of plaggic horizons like high porosity and high SOC contents enable the unhampered penetration by roots. Evidence for modern root remains in buried micro-Podzols was found by Wallinga et al. (2013).
So far neither intensity nor depth of rooting has been determined, especially for buried plaggic horizons located in depths $>0.5 \mathrm{~m}$.

Knowledge on potential rooting of paleosols by younger vegetation is, however, crucial for studies aiming at the reconstruction of various sources of soil organic matter (SOM) input. If only presence of roots is mentioned, but ignored in data interpretation (Andreeva et al., 2013), this complicates also interpretation of molecular markers that are proven to provide insights into paleovegetation and paleoenvironmental conditions (Wiesenberg et al., 2015). This is also crucial for Plaggic Anthrosols, where one might question which type of stable filling was used in a certain area and what was the composition of the applied manure (animal excrements vs. plant remains). Additionally, Plaggic Anthrosols are thought to act as carbon (C) storage (Giani et al., 2014) on the one hand, but on the other hand they tend to soil degradation during self-restoration, i.e., recultivation of the ecosystem without anthropogenic intervention. Soil degradation includes, among other factors, a decrease of $\mathrm{C}$ stocks (Lal, 1994). Long-term $\mathrm{C}$ dynamics in deep subsoil and in paleosols are still largely unknown and might be affected by root penetration and associated rhizosphere processes (Rasse et al., 2005). Hence, root penetration might significantly influence $\mathrm{C}$ storage and dynamics even a long time after pedogenesis of buried soils, thus entailing problems in terms of paleoenvironmental interpretations and soil functioning as $\mathrm{C}$ source or sink.

The aims of this study were to elucidate (i) whether buried soils provide beneficial growth conditions for deep roots, (ii) whether deep roots utilize the soil volume below $0.5 \mathrm{~m}$ and in deeper parts on identical or different scales in terms of utilized volume compared to topsoil and shallow subsoil, and (iii) to which degree depth distribution of different root sizes is related to given physical and chemical soil profile characteristics. These investigations should give insights into the complexity of soil formation phases, which can partially overlap in Late Glacial eolian deposits associated with Holocene (paleo)soils. Therefore, a profile in the southeastern Netherlands that comprises two distinct podzolization phases on sandy parent material, interrupted by anthropogenic plaggen use, was investigated for a suite of physical and geochemical parameters as well as root quantities, using a non-traditional pseudo-three-dimensional approach for assessment of roots.

\section{Methodology}

\subsection{Study site}

The hamlet of Bedaf is located near Uden, in the Maashorst area, southeastern Netherlands $\left(51^{\circ} 40.189^{\prime} \mathrm{N}, 5^{\circ} 34.660^{\prime} \mathrm{E}\right.$; Fig. 1a). Vegetation and land use history of the region were comprehensively investigated by Van Mourik et al. (2012). Briefly, clearing of the natural deciduous forest growing 
on Late Glacial to Preboreal eolian cover sand deposits started in Late Bronze Age and caused transition into heathland. Plaggen agriculture started during the Middle Ages ca. AD 1500 with thicknesses of plaggic deposits of up to ca. $1 \mathrm{~m}$. Intensification of land use after AD 1600 and related heath degradation entailed sand drifting (Driessen and Dudal, 1991), and sands were stabilized in the course of the 19th century under naturally regenerated and planted forests.

The soil profile of the current study was named " $R_{2014}$ " to account for its vicinity to the profile "Rakt" described by Van Mourik et al. (2012), which is called " $R_{2012 "}$ " in the following. It was prepared in an oak stand at the east side of the nature reserve "Bedafse Bergen" (Fig. 1b), a sand dune of $>10 \mathrm{~m}$ height that formed during the early Middle Ages and started to deliver major portions of sand, which deposited on the nearby plaggic deposits in the late 18th and early 19th century. The recent vegetation comprises oak (Quercus ruber) with ages of up to 200 years, minor portions of birch (Betula alba) and mountain ash (Sorbus aucuparia), as well as fern (Dryopteris carthusiana) and blackberry (Rubus fruticosus) understorey.

\subsection{Profile preparation and field methods}

The current soil profile has a thickness of ca. $2.4 \mathrm{~m}$, whereas only the mineral soil was subjected to detailed geochemical analysis. The ca. $10 \mathrm{~cm}$ thick (ectorganic) moder layer was excluded from the current study as predominantly different phases of soil formation and the significance of roots in different soil horizons were targeted. A soil pit was prepared at ca. $1 \mathrm{~m}$ distance of a dead ( $<10$ years) standing oak tree at the left (north) side and a living oak tree at the right (south) side. In the pit, material was removed layer by layer in $10 \mathrm{~cm}$ depth increments down to $0.6 \mathrm{~m}$, and in $15 \mathrm{~cm}$ increments from 0.75 to $2.25 \mathrm{~m}$ as described by Gocke et al. (2014a). This sampling resolution was chosen to obtain samples from at least two different depths of each unit instead of pooled samples. To overcome the low thickness of the drift sand, one planar horizontal level was created at $0.25 \mathrm{~m}$ instead of $0.3 \mathrm{~m}$ to include its top and base. The soil-sediment sequence was investigated both at the profile wall and on each of the 18 horizontal areas, with dimensions of the latter accounting for $0.8 \mathrm{~m} \times 1.4 \mathrm{~m}$. Investigation of the material below the soil pit by auger revealed that the base of the cover sand was not reached, and that the groundwater level was in a depth $>3.5 \mathrm{~m}$ at the time of sampling.

Horizontal levels were carefully cleaned by a brush. A grid with a side length of $0.5 \mathrm{~m} \times 0.5 \mathrm{~m}$ subdivided into nine squares was applied to determine quantities of roots, which were then extrapolated to $1 \mathrm{~m}^{2}$ (Gocke et al., 2014a). To account for the various source plants and the significance of root processes in the rhizosphere surrounding the roots of different sizes, a rough size classification of roots was applied, distinguishing between fine (diameter $\leq 2 \mathrm{~mm}$ ), medium (2$5 \mathrm{~mm}$ ) and coarse roots $(>5 \mathrm{~mm})$. Dead and decaying roots were quantified separately from living roots. Double counting at one depth interval, i.e., on the right and the left side of a horizontal area, was performed where either distribution of living and dead roots was inhomogeneous (topsoil at $0 \mathrm{~m}$ ), or where sediment and paleosol material occurred in the same depth interval due to morphology of plow furrows (transition between drift sand and Plaggic Anthrosol at 0.4 m; Fig. 1c). Analogously, roots were quantified also at the profile wall using the same grid (Gocke et al., 2014a). As dimensions of horizontal and vertical levels did not necessarily take into account identical depth intervals, interpolations were made for the data collected at the profile wall. However, as profile wall data were collected at the front of the horizontal levels, the left and the right side walls as well as at the back of the profile wall, averaged data of profile walls were used for the comparison with horizontal levels.

After root counting, at each horizontal level four replicates of soil or sediment were collected as distant as possible from visible roots and root remains. Material was collected as volumetric samples using an Eijkelkamp soil corer with stainless steel cylinders of an inner volume of $100 \mathrm{~cm}^{3}$, each.

\subsection{Physical and geochemical analyses}

Samples were oven-dried at $40^{\circ} \mathrm{C}$ until their weight remained constant, and the dry weight was normalized to $1 \mathrm{~cm}^{3}$ to obtain the dry bulk density. Complete material of each dry sample was sieved and the fraction $<2 \mathrm{~mm}$ was used for the following analyses. Grain size distribution was measured in two replicates per depth. Therefore, an aliquot of each sample was sieved, and $4.0 \mathrm{~g}$ of the fraction $<125 \mu \mathrm{m}$ was analyzed by X-ray sedimentometry (SediGraph 5100; Micromeritics, USA) after dispersing the sample in $50 \mathrm{~mL}$ of $0.5 \%$ sodium hexametaphosphate solution (Müller et al., 2009). Color of soils and sediments was analyzed in three replicates per depth using a spectrophotometer (Spectro-Color; Dr. Lange, Germany) as described by Gocke et al. (2014a). Color indices are presented according to CIELAB Color Space $\left(L^{*} a^{*} b^{*}\right.$; CIE, 1931). They indicate lightness $L^{*}$ on a scale from 0 (absolute black) to 100 (absolute white), as well as chromaticity coordinates on red-green $\left(a^{*}\right)$ and blue-yellow $\left(b^{*}\right)$ scales. $\mathrm{pH}$ was determined via $\mathrm{pH}$ meter in three replicates per depth after dispersing $10.0 \mathrm{~g}$ of sample in $50 \mathrm{~mL}$ of $0.01 \mathrm{M} \mathrm{CaCl}_{2}$ solution (Egli et al., 2013) and allowing the soil or sediment to settle for $30 \mathrm{~min}$.

For the following analyses, which were measured in triplicate per depth interval, ca. $10 \mathrm{~g}$ of the fraction $<2 \mathrm{~mm}$ was milled in a ball mill (Retsch MM400; Retsch, Germany). Aliquots between 15 and $40 \mathrm{mg}$ were weighed in tin capsules and analyzed for total $\mathrm{C}$ contents via a $\mathrm{CO}_{2}$ isotopic analyzer (Picarro CRDS G2131-i; Costech Analytical Technologies Inc., US). Tests with hydrochloric acid demonstrated the absence of carbonates throughout the profile; therefore, total $\mathrm{C}$ refers to organic $\mathrm{C}\left(\mathrm{C}_{\mathrm{org}}\right)$. For determination of bulk elemental composition, $5.0 \mathrm{~g}$ of milled sample was poured into a 

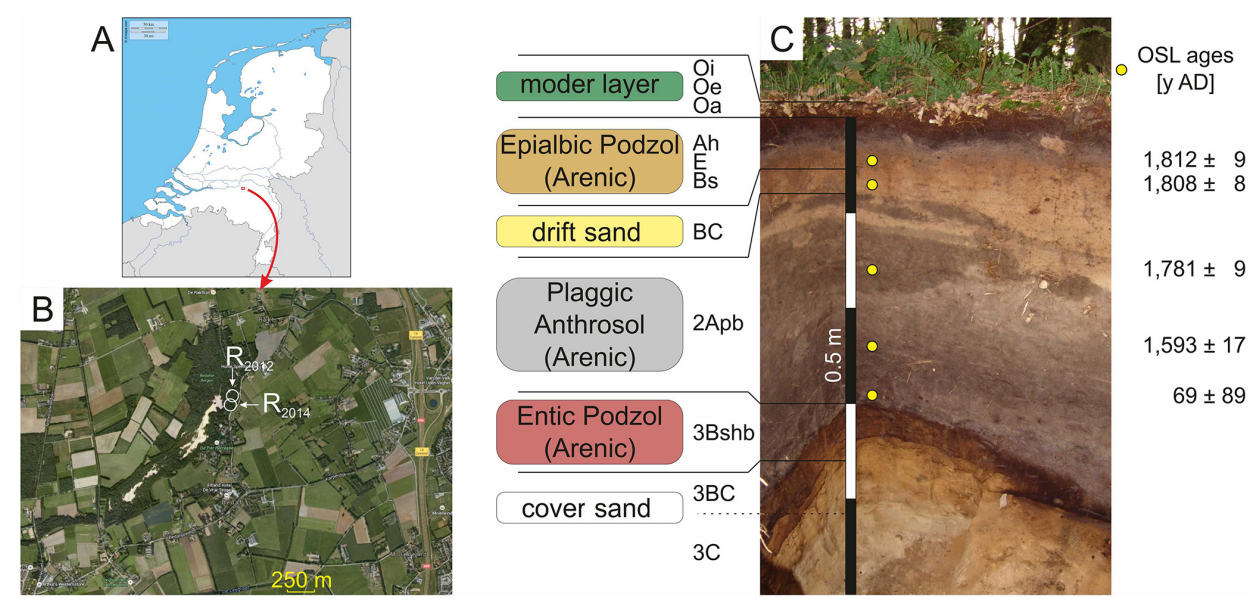

Figure 1. (a) Location of the study site in the Netherlands (source: www.d-maps.com). (b) The nature reserve Bedafse Bergen and its surroundings (source: http://maps.google.de, 17 July 2015). The profile of the current study, " $\mathrm{R}_{2014}$ ", is located approximately $50 \mathrm{~m}$ south of the profile " $\mathrm{R}_{2012}$ " described by Van Mourik et al. (2012). (c) The profile of the current study, $\mathrm{R}_{2014}$, containing several sequences of soil development, reflecting the development of landscape and land use from Late Glacial until today. Optically stimulated luminescence (OSL) ages of drift sand and Plaggic Anthrosol were adopted from the nearby profile $\mathrm{R}_{2012}$ (Van Mourik et al., 2012).

plastic cup, the bottom of which consists of $4 \mu \mathrm{m}$ thin Prolene foil, and measured using an energy-dispersive X-ray fluorescence spectrometer (Spectro X-Lab 2000, Spectro Analytical Instruments, Germany; Egli et al., 2013).

\subsection{Calculations and statistics}

Organic carbon stocks $\mathrm{ST}_{\mathrm{C}}$ were calculated as

$\mathrm{ST}_{\mathrm{C}}=\rho \times d \times C_{\text {org }}$,

where $\rho$ is dry bulk density, $d$ the thickness of the respective depth interval and $\mathrm{C}_{\text {org }}$ organic carbon concentration in $\mathrm{mg} \mathrm{g}^{-1}$ in the individual depth interval.

Depth diagrams show mean values and standard error of the mean. Differences between depth intervals or between units were tested for significance by one-way ANOVA with a significance level of 0.05 and level of high significance 0.01 , followed by post hoc Scheffé test using the software STATISTICA 7.0 (StatSoft).

Crossplots show mean values and standard error of the mean, whereas coefficients of determination were calculated by regression analysis, based on values of individual field replicates.

\section{Results and discussion}

\subsection{Characterization of the profile $R_{2014}$}

From bottom to top, the soil-sediment sequence $\mathrm{R}_{2014}$ comprised the following horizons (FAO, 2006, IUSS Working Group WRB 2014; Fig. 1c): from at least 3.5 to $1.8 \mathrm{~m}$, light yellowish cover sand (3C, cs) dominated, with sporadic orange-reddish mottles between 2.25 and $1.8 \mathrm{~m}$ marking the transition towards the overlying dark reddish-brown
3Bshb horizon of a relict Entic Podzol (Arenic) (1.8-1.5 m; rEP; Fig. 2a). The Podzol developed during several millennia (Sauer et al., 2007) between Preboreal and Bronze Age, likely under deciduous forest until anthropogenic conversion of forest to heath vegetation started (Van Mourik et al., 2012). Podzolization processes including redistribution of $\mathrm{OM}$, iron $(\mathrm{Fe})$ and aluminum $(\mathrm{Al})$ oxides led to the formation of consolidated crusts, which are continuous in its upper part and more interrupted towards the underlying cover sand (cs; Fig. 2b). The upper ca. 0.3 to $0.5 \mathrm{~m}$ of the Podzol, likely including the eluvial and humic horizons, was reworked when plaggic agriculture began and mixed with plaggic deposits, as visible by the presence of sporadic pick marks within the Podzol, filled with plaggic material (Fig. 2c, d). A thick gray Plaggic Anthrosol (Arenic) (PA) was accumulated in $1.5-0.4 \mathrm{~m}$ depth, revealing the darkest color and the most dense, clayey material at the bottom, whereas the material was lighter and more sandy towards the top (Fig. 1c). Using optically stimulated luminescence (OSL) ages from the nearby profile $\mathrm{R}_{2012}$ (Van Mourik et al., 2012), an average rate of plaggen accumulation of $1.6 \mathrm{~mm} \mathrm{yr}^{-1}$ was calculated, which is in agreement with literature data (Giani et al., 2014). The top of the Plaggic Anthrosol is characterized by an irregular boundary, showing the well-preserved morphology of up to $0.2 \mathrm{~m}$ deep and $0.4 \mathrm{~m}$ wide plow furrows, which had been created in lateral distances of ca. $0.9 \mathrm{~m}$ (Figs. 1c, 2e) during the last phases of historic agricultural use at this site. The yellow drift sand (ds) overlying the Plaggic Anthrosol (0.25$0.4 \mathrm{~m}$ ) filled the irregular former surface created by plowing. The profile is terminated by an Epialbic Podzol (Arenic) (0$0.25 \mathrm{~m}$; EP) at its top. Due to its young age of ca. 200 years (Van Mourik et al., 2012), eluvial and illuvial horizons are 
weakly developed but well visible (Sauer et al., 2007). The complete succession of horizons is shown in Fig. 1c.

\subsection{Physical and geochemical characterization of the $\mathrm{R}_{2014}$ profile: distinction of soil formation phases}

Dry bulk density, with a range between 1.32 and $1.64 \mathrm{~g} \mathrm{~cm}^{-3}$ (Fig. 3) and an average of $1.51 \pm 0.02 \mathrm{~g} \mathrm{~cm}^{-3}$, was in agreement with global values usually falling in the range of $1.1-1.6 \mathrm{~g} \mathrm{~cm}^{-3}$ (Hillel, 1980). Comparably low density between 1.43 and $1.50 \mathrm{~g} \mathrm{~cm}^{-3}$ agreed with literature data on other plaggic soils (Giani et al., 2014). The highest values $\geq 1.54 \mathrm{~g} \mathrm{~cm}^{-3}$ were restricted to cs, ds and the lowermost part of the EP, thus confirming the general observation of high dry bulk densities in sand-dominated soils and sediments.

Grain size distribution showed a general dominance of the sand fraction with $90.2-99.2 \mathrm{wt} \%$, with values $<95 \mathrm{wt} \%$ being restricted to the PA between 0.6 and $1.35 \mathrm{~m}$ (Fig. 3). Remarkable portions of silt $>4 \mathrm{wt} \%$ and of clay $>2 \mathrm{wt} \%$ occurred solely in the mentioned depth interval. Similarities between grain size distribution of the EP with that of cs and ds are likely due to the short time in which the recent soil developed (Van Mourik et al., 2012).

Color indices largely confirmed field observations, with the highest $L^{*}$ values (lightest color; $>57$ ) occurring in the cs and lowest values (darkest color; $<52$ ) in the rEP and major parts of the PA (Fig. 3). The dark color might be linked to high contents of OM, which is however not necessarily valid for the sand fraction (Wiesenberg et al., 2006). The continuous increase of $L^{*}$ towards the top of the PA likely resulted from increasing incorporation of drift sand, and potentially also from decreased heath biomass production during the Little Ice Age, which peaked in the late 17th century (PAGES 2k Consortium, 2013), with heath sods containing relatively less plant material and more mineral soil. The redness of the profile was typically highest (highest $a^{*}$ values $>1.8$ ) in the lowermost parts of both Podzols as well as in directly underlying sand, which indicates the effect of podzolization processes like Fe accumulation (Sauer et al., 2007) extending into soil parent material (see also Fig. 2a). In addition, $b^{*}$ (see Supplement Table S1) showed the highest values (yellow color; > 10) in cs and constantly low values (blue color; mostly $<5$ ) in the PA.

The complete soil-sediment sequence showed acidic conditions with $\mathrm{pH}$ values between 3.1 and 4.7 (Fig. 4), and an average of $4.0 \pm 0.1$, explained by the absence of $\mathrm{CaCO}_{3}$. Within both the EP and the rEP, the $\mathrm{pH}$ increased consequently from the respective top towards underlying sand from 3.1 to 3.7 and from 4.1 to 4.7 , respectively, whereas values in the PA were in between both soil-sediment couples.

Organic carbon $\left(\mathrm{C}_{\text {org }}\right)$ contents showed a wide range between 0.6 and $17.9 \mathrm{mg} \mathrm{g}^{-1}$ (Fig. 4), averaging $7.1 \pm 1.3 \mathrm{mgg}^{-1}$. In contrast to extremely $\mathrm{C}_{\text {org }}$-poor cs and ds horizons $\left(<0.3 \mathrm{mg} \mathrm{g}^{-1}\right)$, high $\mathrm{C}_{\text {org }}$ contents ( $>10 \mathrm{mg} \mathrm{g}^{-1}$ ) were found in the topsoil as well as in lower PA and rEP (1.05-1.65 $\mathrm{m}$ depth), matching the range of $\mathrm{C}_{\text {org }}$ reported for Plaggic Anthrosols (Pape, 1970). This observed peak of $\mathrm{C}_{\text {org }}$, together with decreasing $\mathrm{C}_{\text {org }}$ contents towards the top of the PA, likely resulted from increasing accumulation rates of mineral soil material over time (see above). The negative correlation of $\mathrm{C}_{\text {org }}$ contents with $L^{*}$ $\left(R^{2}=0.84\right.$; Supplement Fig. S1a) reinforced the assumption that high OM contents caused the dark color (Schulze et al., 1993; Konen et al., 2003), despite uncertainties due to its sandy nature. Total $\mathrm{C}$ stock of the investigated profile $(0-2.4 \mathrm{~m})$ was $27.4 \mathrm{~kg} \mathrm{~m}^{-2}$. A total of $64 \%$ of the total C stock was located in the PA, whereas EP and rEP comprised solely 9 and $18 \%$, respectively, corresponding to 2.5 and $5 \mathrm{~kg} \mathrm{~m}^{-2}$ (Fig. 5a). The latter two values were in the lower and medium range of $\mathrm{C}$ stocks reported for European forest soils (Baritz et al., 2010), which is due to the young age of the EP and incompleteness of the rEP. Minor portions comprising 4 and $5 \%$ of the $\mathrm{C}$ stocks were found in ds and cs. Thus, major portions of $\mathrm{C}$ stocks were located below $1 \mathrm{~m}$ depth $\left(17.7 \mathrm{~kg} \mathrm{~m}^{-2}\right.$; Fig. $\left.5 \mathrm{~b}\right)$. The current study not only confirms the important role of deep forest soils for terrestrial C pools (Harrison et al., 2011; Lorenz et al., 2011) but also enforces the rising awareness of buried soils as important terrestrial C pools, as recently discussed by Marin-Spiotta et al. (2014) and Johnson (2014). Implementation of deeper parts of soil and parent materials is thus crucial for terrestrial C budgets but has been performed only scarcely so far (e.g., Wiesmeier et al., 2012; Harper and Tibbett, 2013).

Throughout major parts of the profile, the abundance of nutritional elements phosphorous $(\mathrm{P})$, calcium $(\mathrm{Ca})$ and $\mathrm{Fe}$ was low, with highest values of $0.12,0.11$ and $0.79 \mathrm{wt} \%$, respectively (Fig. 4; for further elemental composition see Supplement Table S1). Due to the exposition of plaggen sods to animal excrements and household garbage prior to spreading on the field, as well as low P translocation in soils (Giani et al., 2014), relative $P$ contents were highest in the PA and especially in its lowermost part. Relative enrichment of $\mathrm{P}$ proceeding into the rEP suggests limited depth translocation of certain nutritional elements due to leaching processes, significantly later than the time span of podzolization. A clear difference occurred only between the uppermost $1.8 \mathrm{~m}$ and the cs, in which most elements were depleted due to the high abundance of silicon $(\mathrm{Si})$ from quartz grains. Ca was slightly enriched ( $>0.08 \mathrm{wt} \%$ ) compared to other profile layers only at the top of EP and in cs. The general Fe enrichment in plaggen soils observed by Giani et al. (2014) could not be confirmed for the profile investigated in the current study. Rather, Fe contents were similar throughout the profile $(0.2$ $0.4 \mathrm{wt} \%$ ) with slightly increasing trend towards deeper parts of the PA and only one distinct peak of $0.8 \mathrm{wt} \%$ at the top of the rEP (Fig. 4). The latter is rather related to former podzolization (Sauer et al., 2007) than subsequent plaggen accumulation. As a consequence of this depth distribution, no 

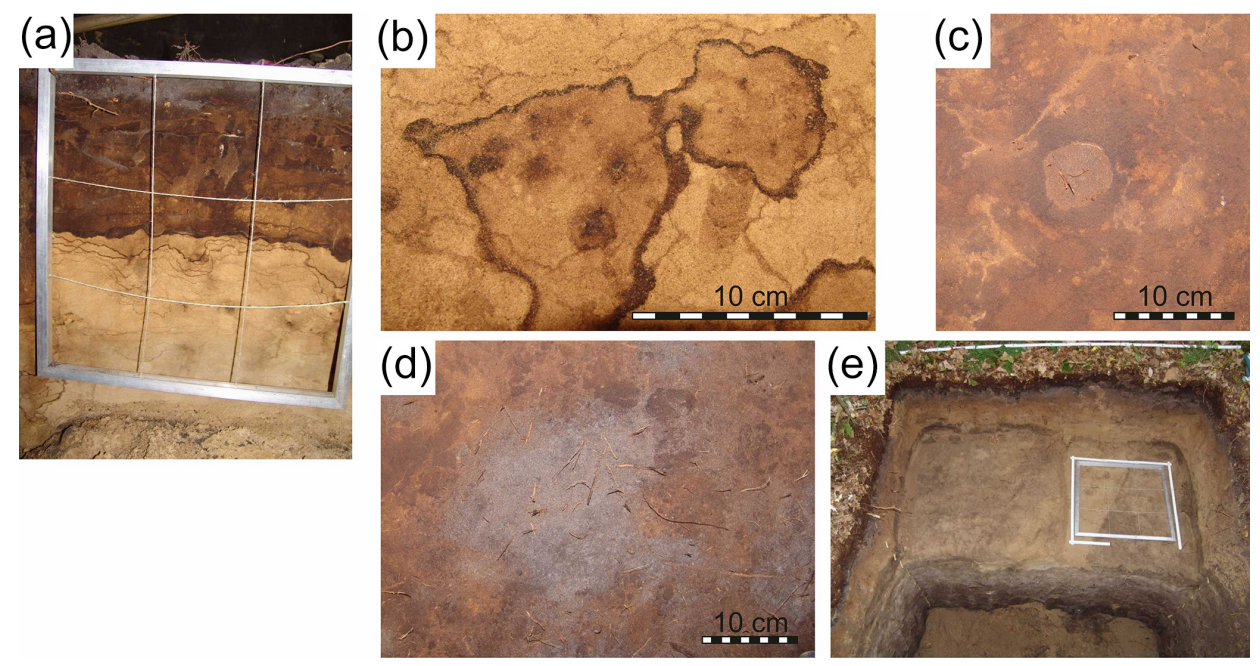

Figure 2. Detailed pictures of the profile, with (a) showing the profile wall and (b-e) displaying view on horizontal levels. Note that the inner length of the square-shaped aluminum frame is $0.5 \mathrm{~m}$. (a) Depth interval $1.5-2 \mathrm{~m}$ with clearly visible boundary between the relict Entic Podzol (rEP) and cover sand (cs). (b) Decomposed roots surrounded by dark accumulations of humic material and iron and manganese oxides at $1.8 \mathrm{~m}$ depth. (c, d) Pick marks in the rEP (reddish-brown) filled with gray plaggic material at 1.65 and $1.5 \mathrm{~m}$ depth, respectively. (e) Top of the Plaggic Anthrosol (PA) with visible plow furrow crossing the horizontal level diagonally, filled with yellow drift sand (ds). The left half of the horizontal layer is located at $0.4 \mathrm{~m}$ depth, the right half at $0.5 \mathrm{~m}$ depth.

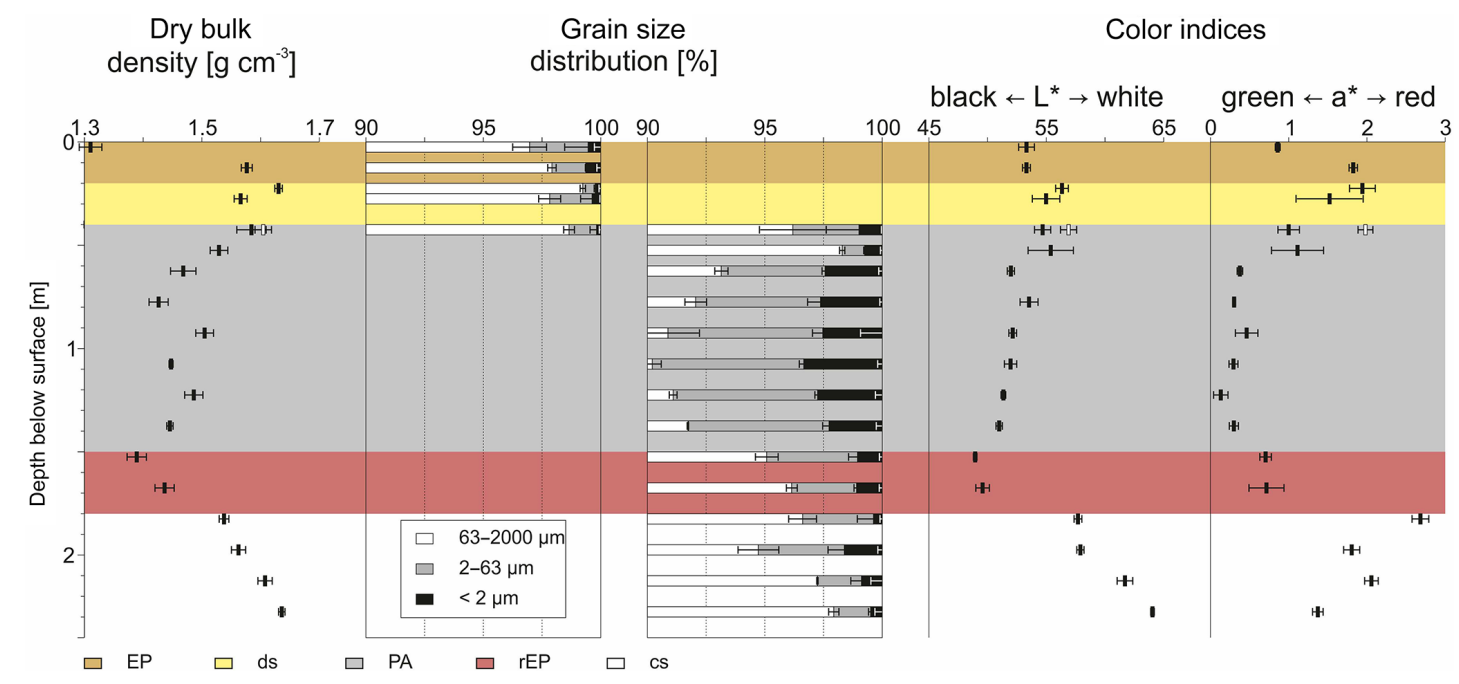

Figure 3. Physical properties of the profile, including dry bulk density, grain size distribution (left part of the diagram shows EP and ds horizon, right part reveals PA, rEP and cs), as well as color indices $L^{*}$ (lightness) and $a^{*}$ (redness). Symbol and column height represent thickness of sampled interval $(0.05 \mathrm{~m})$. At $0.4 \mathrm{~m}$ depth, ds (white symbols) and PA (black symbols) were analyzed separately.

correlation of Fe with $a^{*}$ was found (Supplement Fig. S1b). Potentially, Fe coatings around sand grains might themselves be coated with OM translocated to a later point in time as discussed for Podzols (Anderson et al., 1982). This is supported by a strong correlation of $\mathrm{Fe}$ with $\mathrm{C}_{\text {org }}$ within the PA $\left(R^{2}=0.94\right.$; Fig. S1c). Thus, the most probable mechanism of OM immobilization in the PA at Bedafse Bergen seems to be the adsorption on secondary Fe precipitates, whereas stabilization by clay can be excluded due to low clay con- tents, and similarly no correlation of $\mathrm{C}_{\text {org }}$ with $\mathrm{Al}$ was found (Fig. S1d).

The following similarities and differences in physical and geochemical properties between different layers and horizons supported distinction of the respective (paleo)pedogenic phases. The PA showed two characteristic features: on the one hand very high $\mathrm{C}_{\text {org }}$ content in the range of surface soil, significantly higher than that of cs and ds, and on the other hand significant enrichment ( $\mathrm{P}$, sulfur $(\mathrm{S})$, copper $(\mathrm{Cu})$, molybdenum (Mo); Fig. 4 and Table S1) and depletion 


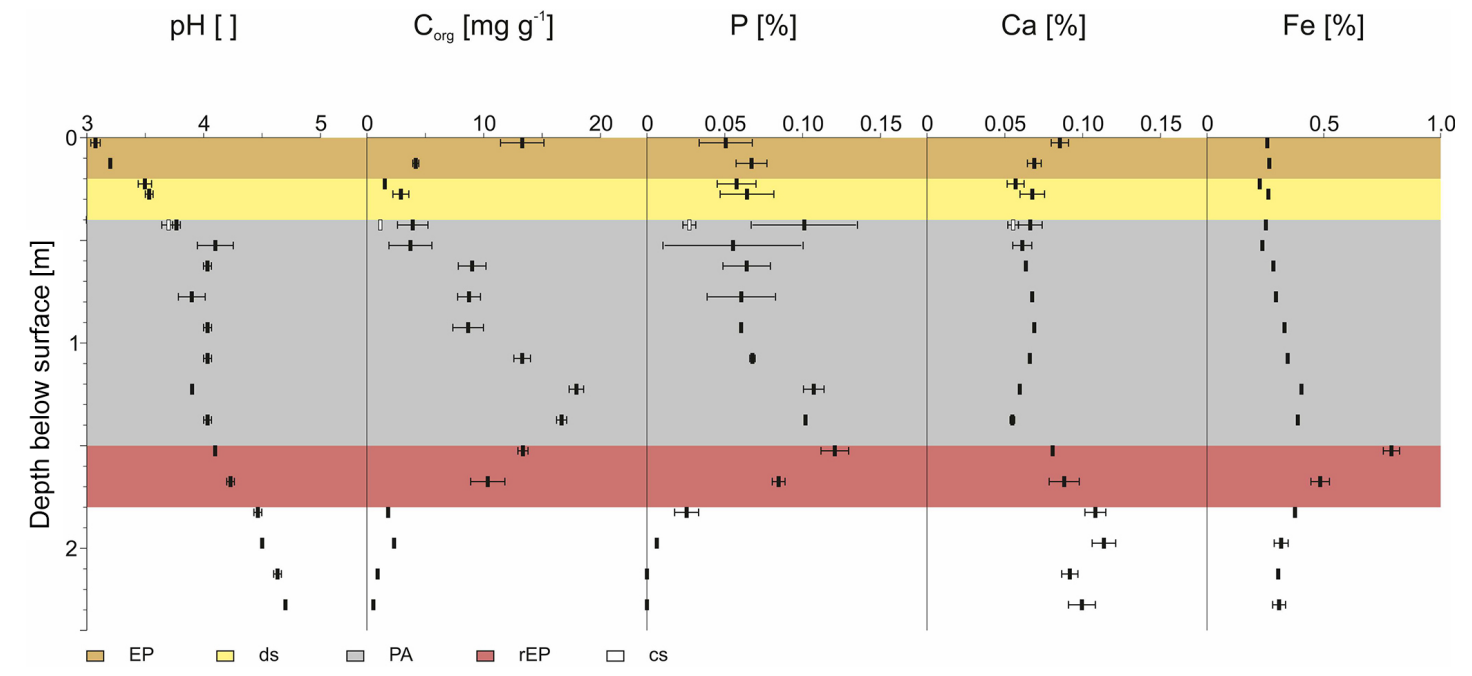

Figure 4. Geochemical properties of the profile, including $\mathrm{pH}, \mathrm{C}_{\mathrm{org}}$ contents, and weight percentages of $\mathrm{P}$, Ca and Fe. Symbol and column height represent thickness of sampled interval $(0.05 \mathrm{~m})$. At $0.4 \mathrm{~m}$ depth, drift sand (white symbols) and PA (black symbols) were analyzed separately.

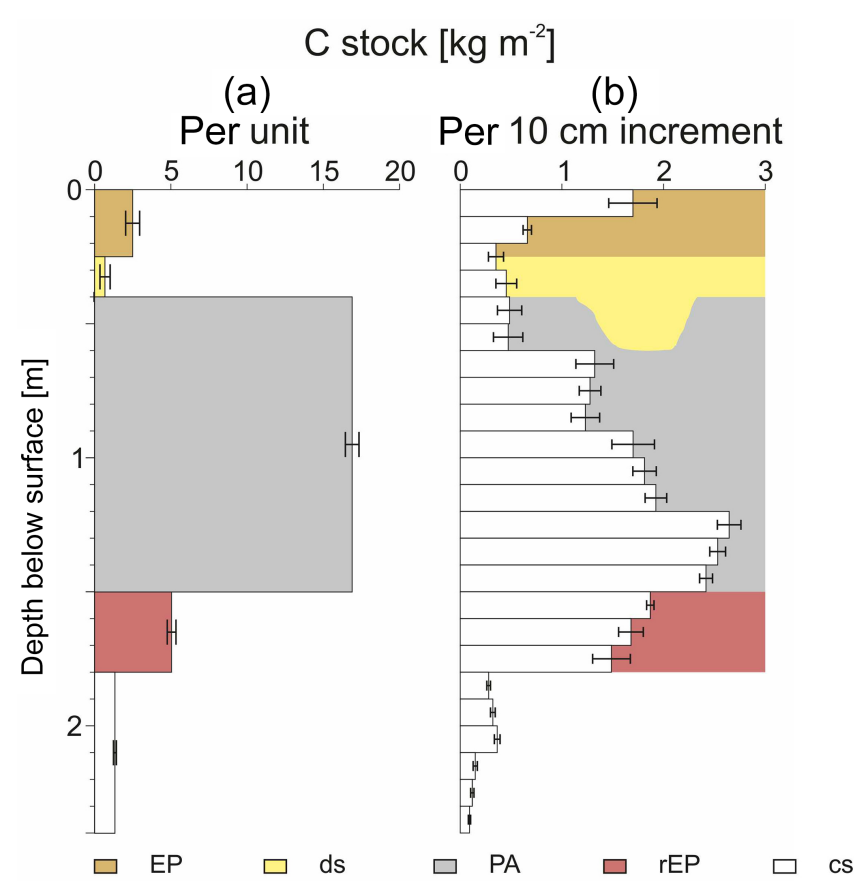

Figure 5. $\mathrm{C}_{\text {org }}$ stocks of the profile $\mathrm{R}_{2014}$, calculated (a) for each unit and (b) per $10 \mathrm{~cm}$ depth increment.

( $\operatorname{sodium}(\mathrm{Na})$, potassium $(\mathrm{K}), \mathrm{Ca}$; Table $\mathrm{S} 1)$ in certain nutritional elements compared to cs and ds. Both features were highly significant (for Mo solely in the lower half of PA) and partially proceeded into $\mathrm{rEP}$. The latter indicates that downward transport of these elements continued after transformation of the Podzol into a Plaggic Anthrosol. Additionally, constant or scattering values of several parameters (density, grain size, $a^{*}, L^{*}, \mathrm{pH}, \mathrm{Mg}$; Figs. 3, 4 and Table S1) instead of a depth gradient within PA confirmed the accumulation of sods and their mixing by plowing, contrary to a natural soil that would have developed systematically from top to bottom. Nevertheless, several parameters, e.g., increasing bulk density, increasing sand fraction as well as decreasing $\mathrm{C}_{\text {org }}$, indicated the increasing portions of drift sand incorporated into PA towards its top. Both Podzols, although differing in absolute age by several millennia and in their developmental stage, showed similar depth trends in terms of $\mathrm{pH}$ and color indices: the strongest acidification occurred in the topsoil and the top of rEP respectively, whereas a highly significant increase of $\mathrm{pH}$ was determined from top to bottom of $\mathrm{EP}$ and $\mathrm{rEP}$, and partially from the bottom of the respective (paleo)soil into soil parent material (Table S2). A highly significant increase both of $a^{*}$ and of $L^{*}$ with depth, the latter exceeding into cs in the case of rEP, confirmed the effect of podzolization processes including eluviation and illuviation of Fe and other constituents. Similarly, cs and ds resembled each other and could be clearly distinguished from respective overlying (paleo)soils due to higher dry bulk density and $\mathrm{pH}$ and lower contents of nutritional elements $(\mathrm{P}, \mathrm{S})$ and $\mathrm{C}_{\mathrm{org}}$. These differences were highly significant for the rEP-cs couple and partially significant for the couple of EP and ds (Table S2).

\subsection{Root distribution: traditional vs. new approach}

Living roots were present throughout the uppermost $2 \mathrm{~m}$ of the profile, when detected and quantified on horizontal levels (Fig. 6). Fine roots might derive from trees or from understorey vegetation, whereas medium and coarse roots are exclusively formed by the nearby mature shrubs and trees. Living roots below ca. $0.5 \mathrm{~m}$ depth are likely attributed to 


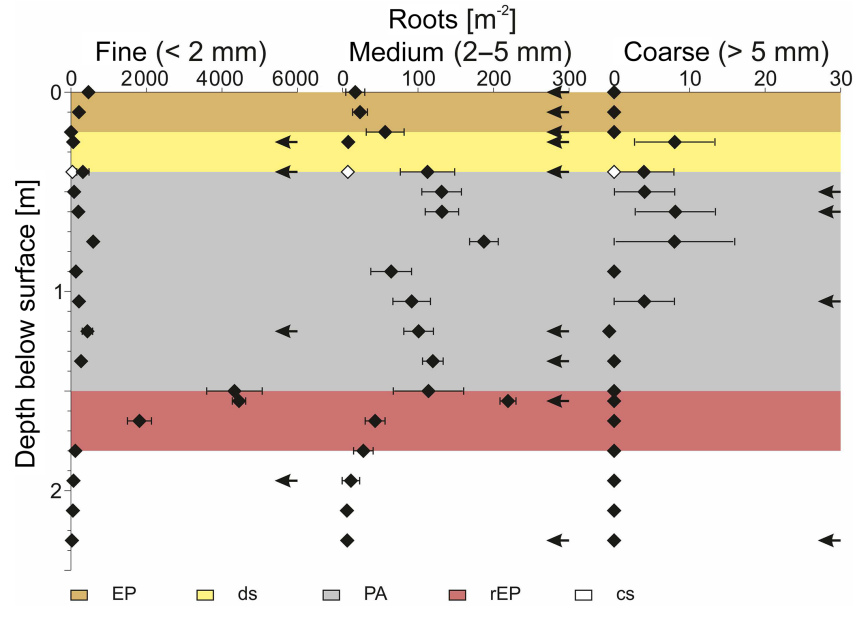

Figure 6. Depth distribution of living roots, quantified on horizontal levels, and presence of decomposed roots (if abundant; $<10 \mathrm{~m}^{-2}$ not counted), marked by an arrow. Position of the symbols marks the surface of the respective horizontal level. At $0.4 \mathrm{~m}$ depth, drift sand (white symbols) and PA (black symbols) were analyzed separately.

oak trees, whereas shallow roots may originate from various source plants of the present vegetation. In agreement with previous observations (Millikin and Bledsoe, 1999; Moreno et al., 2005; Thomas, 2000), frequencies of fine roots decreased continuously from topsoil $\left(454 \pm 65 \mathrm{~m}^{-2}\right)$ towards bottom of $\mathrm{ds}\left(16 \pm 11 \mathrm{~m}^{-2}\right)$. However, fine roots increased again within the PA, slightly exceeding topsoil frequency for the first time at $0.75 \mathrm{~m}\left(588 \pm 81 \mathrm{~m}^{-2}\right)$ and maximizing with $>4000 \mathrm{~m}^{-2}$ in the upper part of the $\mathrm{rEP}$. This factor $\approx 10$ between topsoil root quantities and values in $1.5 \mathrm{~m}$ depth strongly contradicts the general assumption of rooting being largely restricted to the topsoil. Contrary, solely $5 \%$ of total fine roots, $2 \%$ of total medium roots and none of the coarse roots appeared in the topsoil, whereas 24,74 and $78 \%$ occurred within the PA, respectively. Further, $78 \%$ of fine roots, $42 \%$ of medium roots and $11 \%$ of coarse roots grew below the uppermost $1 \mathrm{~m}$, respectively. The ability of plant roots to grow down to several meters has been known for decades (Canadell et al., 1996) but has been largely ignored in soil science so far (Maeght et al., 2013). Below $1.5 \mathrm{~m}$, fine roots strongly decreased and were absent below $2 \mathrm{~m}$ (Fig. 6). Medium roots showed a completely different depth distribution, with very low abundances $\left(<60 \mathrm{~m}^{-2}\right)$ in the uppermost $0.4 \mathrm{~m}$ and between 1.65 and $2.25 \mathrm{~m}$ depth, whereas quantities were mostly $>100 \mathrm{~m}^{-2}$ throughout the PA and uppermost rEP (Fig. 6). Another distribution pattern was found for coarse roots, the occurrence of which strongly varied within each depth interval and was restricted to a depth between $0.25 \mathrm{~m}$ and $1.05 \mathrm{~m}$ (Fig. 6), confirming previous observations (Millikin and Bledsoe, 1999). A dissimilar depth distribution of different root sizes could be expected, as these perform different tasks like nutrient acquisition and anchorage

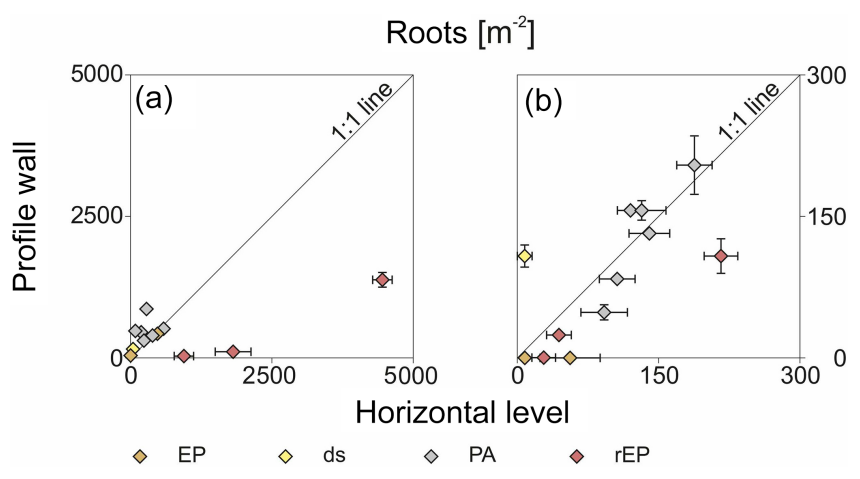

Figure 7. Comparison of (a) fine- and (b) medium-root quantities determined at the profile wall at the right side of the soil pit, and those determined on horizontal levels.

(e.g., Coutts et al., 1999; Hodge et al., 2009). Nevertheless, similarities were found at three depth intervals. First, frequencies of fine, medium and coarse roots were lowest in nutrient-poor cs. Second, they showed a bimodal pattern at $0.4 \mathrm{~m}$, with lower values in ds compared to PA. The difference was highly significant for medium roots. Third, fine and medium roots were most abundant at the transition between PA and rEP. In the latter, roots occurred predominantly in former pick marks filled with plaggic material (Fig. 2c, d). Only scarcely, the comparatively hard sesquioxide crust of the rEP was directly penetrated by fine and medium roots. These observations imply that roots exploit deeper parts of the soil and soil parent material in search of preferable growth conditions, including, e.g., abundant nutrients (see Sect. 3.4; Sainju and Good, 1993).

Ancient roots with various degree of decomposition were observed at several depths, but these occurrences did not match with abundances of living roots (Fig. 6). For instance, decomposed fine roots occurred mainly in the ds and cs horizons, whereas decomposed medium roots were found in several depth intervals from topsoil down to cs. Decomposed coarse roots occurred at similar depths as living coarse roots and additionally also at $2.25 \mathrm{~m}$. Concluding, ancient roots within the EP, ds and PA derived from recent vegetation. In contrast, those at the bottom of the soil pit likely originated from source vegetation other than the modern one, i.e., probably from deciduous trees leading to the formation of the buried Podzol. This demonstrates that deep roots, exceeding the actual soil depth and proceeding into underlying soil parent material or paleosols, are not a special phenomenon of recent vegetation but occurred also at earlier times.

The reason why deep roots have been mostly neglected and their abundance has been strongly underestimated so far is that root quantification - if at all - was commonly performed at the profile wall for fast and convenient investigation (Thomas, 2000), as root length density in collected soil samples (Moreno et al., 2005) or weighed biomass after excavation (Millikin and Bledsoe, 1999). Detailed root 
investigation on horizontal levels of respective dimensions, as presented in the current study, is scarce. Figure 7 shows the limited informative value of studies using either one or the other approach, especially in the case of fine roots (Fig. 7a). For these, quantification at the profile wall yielded considerably lower values than quantification on horizontal levels in depths with generally low and intermediate frequency $\left(<1000 \mathrm{~m}^{-2}\right)$, whereas very high abundances in the rEP were strongly underestimated at the profile wall. These considerable differences between both approaches likely are attributed to contrasting living conditions within the current soil profile. That is, compactness at the top of the rEP forces fine roots to grow more vertically and beneficial nutritional conditions in the PA rather entail spreading of fine roots and thus a higher portion of diagonally and horizontally growing roots, which are registered by profile wall counting better than by horizontal counting. For medium roots, quantities obtained by the two approaches matched better $\left(R^{2}=0.14\right.$; Fig. 7b), with deviations from the $1: 1$ line usually $<20 \%$. Larger divergences occurred, however, in those depths where frequencies determined on horizontal levels are either very low like in ds or very high like in rEP. Medium root frequencies were further largely underestimated by wall quantification especially in the EP including the topsoil, which is most commonly studied for root abundances, whereas deeper parts $(>1 \mathrm{~m})$ are scarcely considered in terms of roots (Perkons et al., 2014). In summary, quantification of roots exclusively at the profile wall can underestimate fine roots, whereas combination with counting on horizontal levels might give a more comprehensive insight into root distribution, as well as improved understanding of the possible reasons. In addition to depth distribution and preferred rooting direction, the approach chosen for the current study revealed the high variability of root abundances even within short distances of up to $1.4 \mathrm{~m}$, the side length of the soil pit (Fig. 8a, b).

\subsection{Beneficial and unfavorable rooting conditions in the soil-sediment sequence $R_{2014}$}

The following parameters pointed to preferable or nonpreferable rooting conditions in respective units of the soilsediment sequence like especially the PA.

Negative correlation of fine roots with dry bulk density in the buried soils and sediments, excluding $\mathrm{EP}\left(R^{2}=0.29\right.$; see Fig. S1e), confirmed the previous suggestion of preferable rooting conditions provided by low-density substrates with high porosity (Driessen and Dudal, 1991). In addition, plaggic horizons commonly contain enhanced contents of both total and plant-available P (Eckelmann, 1980); therefore, high total $\mathrm{P}$ in $\mathrm{R}_{2014}$ suggests a similar situation in the profile of the current study. Here, very likely roots exploited the buried PA for P (and S), whereas other nutritional elements like $\mathrm{K}$ or $\mathrm{Ca}$ are less relevant at that site. However, only a positive trend instead of a clear correlation was found between fine roots and $\mathrm{P}\left(R^{2}=0.20\right.$; Fig. S1f $)$ as well as medium roots and $\mathrm{P}\left(R^{2}=0.32 ;\right.$ Fig. $\left.\mathrm{S} 1 \mathrm{~g}\right)$ in the buried soils and sediments, excluding EP. Due to low mobility of P, we suggest that the original P contents in PA have been considerably higher prior to penetration by the recent vegetation, and that major parts of $\mathrm{P}$ were transported towards the topsoil via vertical nutrient uplift within root systems (Jobbàgy and Jackson, 2001; Kautz et al., 2013). This is further enforced by a high variation of $\mathrm{P}$ contents between replicates in upper PA (Fig. 4), which coincides with spatially highly varying root abundances (Fig. 8).

Contrary to these positive growth conditions for roots, rEP provided a special situation with very abundant fine and medium roots on its top. This is most likely caused by a combination of two factors. First, high Al contents in the rEP (Table S1) potentially lead to Al toxicity for plant roots; thus, fine roots penetrate rEP only a few centimeters and preferentially grow in pick marks filled with plaggic material, preventing the contact with $\mathrm{rEP}$. The high $\mathrm{Al}$ concentrations can lead to inhibition of further root growth (Ryan et al., 1992; Poschenrieder et al., 2008) and might further promote the generation of abundant fine roots $\left(R^{2}=0.62\right.$; Fig. S1h $)$ by the plant to "search" for other, more beneficial regions in the soil. Second, the enrichment of $\mathrm{Fe}$ and manganese (Mn) oxides which coat the sand particles and form encrustations in the rEP leads to a higher compactness and thus inhibits further root penetration in major areas of the horizon. These encrustations also lead to a reduction in the pore size, leading to enhanced water and air permeability, but limited root penetration. The latter effect is well known for cemented soil horizons with spodic or other properties (Bockheim, 2011). Strongly decreasing root abundances below the top of rEP result from minor possibility for the plant roots to penetrate the sesquioxide accumulations.

\subsection{Implications for pedology, paleoenvironmental records and carbon sequestration potential}

The intensive penetration of the soil-sediment sequence $\mathrm{R}_{2014}$ by various generations of plants, including ancient deciduous trees associated with rEP (van Mourik et al., 2012), agricultural plants associated with PA and recent mixed forest associated with EP (Fig. 9), might have considerable consequences for pedology, the recorded paleoenvironmental, landscape developmental and cultural signal on the one hand, and for the potential to sequester or release $\mathrm{C}$ on the other hand.

Young (Holocene) buried soils have a high value for reconstruction of regional and local vegetation, land use and history. Therefore, traditionally the record is investigated via pollen records (e.g., Van Mourik et al., 2012) and archeological artifacts (e.g., Wells, 2004), which are not influenced by later root penetration. However, in the last decades molecular approaches including plant- and microorganism-derived lipids, as well as isotopic analyses $\left(\delta^{13} \mathrm{C}, \delta^{2} \mathrm{H}, \Delta^{14} \mathrm{C}\right)$ on $\mathrm{OM}$ and fractions thereof, became of increasing interest to 

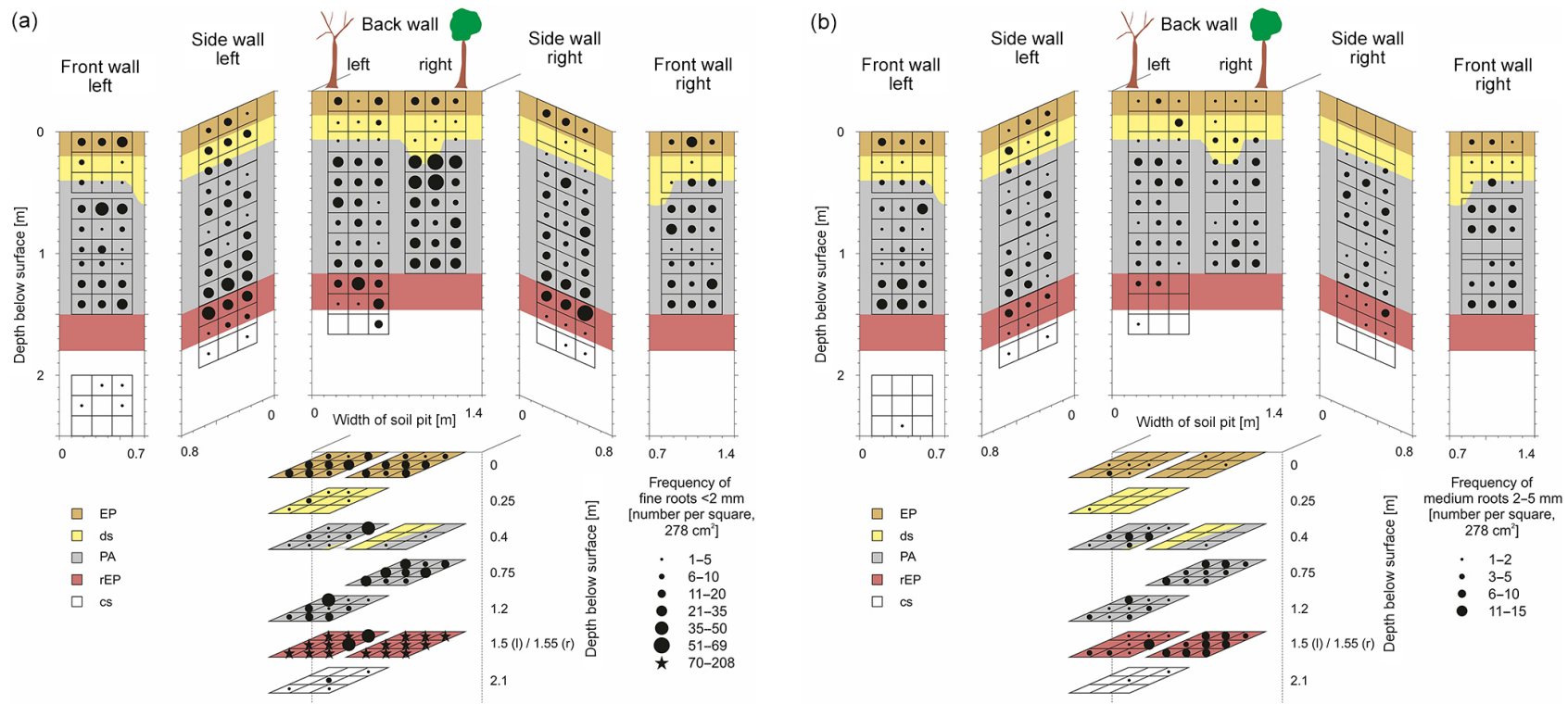

Figure 8. Frequencies of (a) fine and (b) medium roots determined at different places within the soil pit.
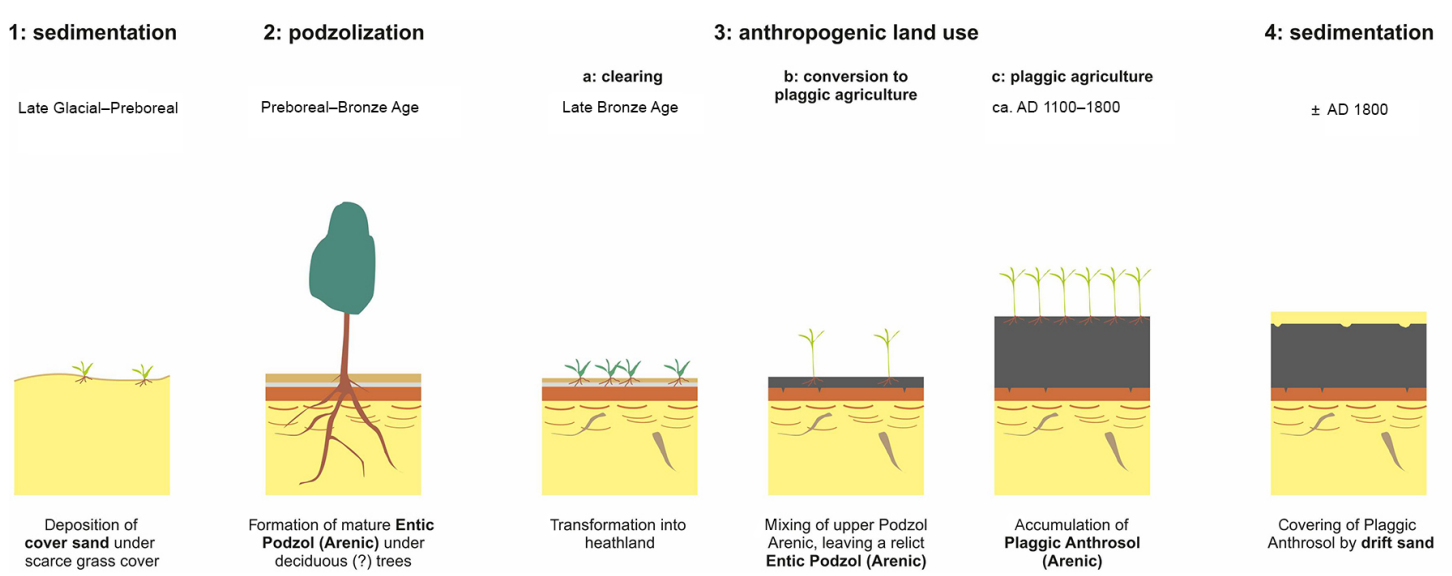

5: podzolization
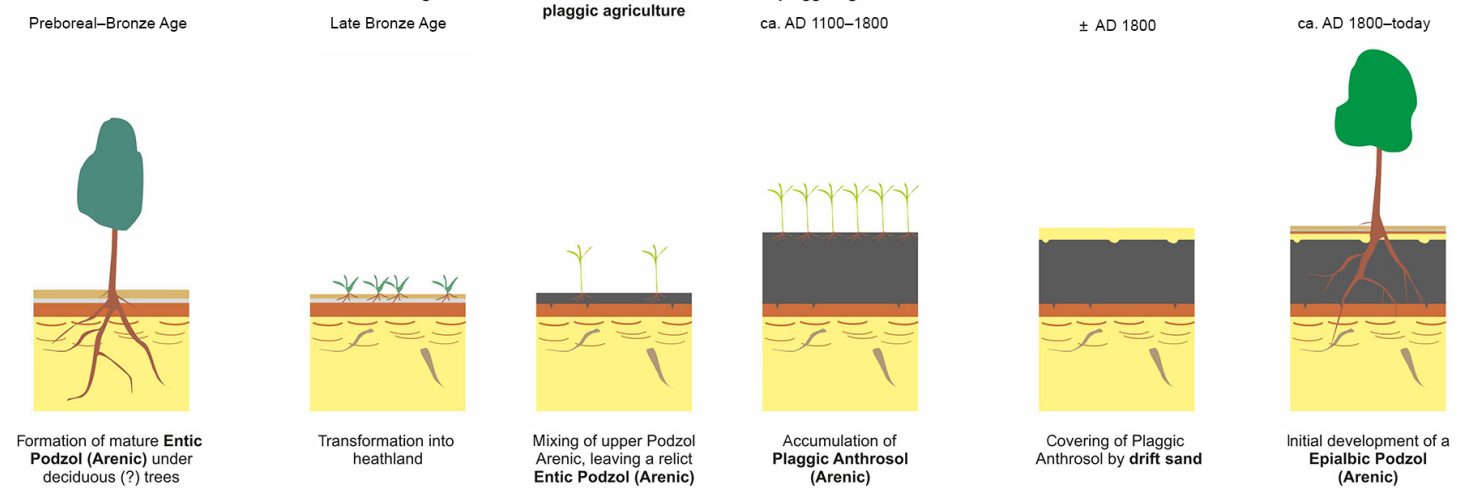

Figure 9. Schematic figure of the successive phases of sedimentation and soil formation that led to the development of the investigated profile.

get improved insights into paleovegetation composition, paleohydrological conditions and time span of OM incorporation in soil (e.g., Sachse et al., 2009; Mendez-Millan et al., 2014; Wiesenberg et al., 2015). These proxies can be considerably overprinted by incorporation of younger rootand microorganism-derived $\mathrm{OM}$ in surrounding sediment up to several centimeters distant from roots, entailing uncertainties in terms of reliability of the proxies (Huguet et al., 2012; Gocke et al., 2014b). Based on pyrolysis-GC/MS, Van Mourik et al. (2010) reported the incorporation of presumably both above- and belowground biomass from heath vegetation in buried plaggic soils of the Maashorst area, thus emphasizing the meaning of root biomass, however without discussing the potential subsequent disturbance of the chronological context within the sequence. Also, ${ }^{14} \mathrm{C}$ dating of hu- mic acids from the PA in the nearby profile Nabbegat (Van Mourik et al., 2012) yielded consistently increasing ages with depth and did not indicate any overprint by recent roots. However, detection of incorporated root-derived OM of considerably younger age, assumed based on the here shown root distribution, has not been tried yet and may largely affect the paleoenvironmental record on a molecular level. The different phases and sources of molecular proxies in recent and buried soils can be deciphered based on modeling including simple end-member models (Buggle et al., 2010). In contrast, the complexity of multiple sources of different root and aboveground biomass requires more sophisticated approaches combining various sets of biomarkers of potential source vegetation, as successfully applied in the VERHIB model (Jansen et al., 2010). Such an approach might 
enable not only the assessment of different sources of OM in soils of different ages but potentially also the quantification of the recent root overprint of the paleoenvironmental record, and the correction of the paleoenvironmental signal biased by the root overprint. However, such an unraveling depends strongly on accurate information about root input and rooting depth (Van Mourik and Jansen, 2013). Therefore, a combined application with the root estimating methodology described in the present study would appear very promising.

It is known that plaggic soils may act as carbon storage (Giani et al., 2014). However, long-term stability of incorporated OM depends not only on chemical composition and thus portions of above- and belowground biomass (Rasse et al., 2005) but also on physical and chemical properties of the soil and soil parent material as well as environmental conditions (Schmidt et al., 2011). Commonly, roots are thought to introduce additional OM to soil. Therefore, Kell (2012) suggested the application of deep-rooting crops to sequester C. However, potential priming effects have to be considered, leading to mineralization not only of fresh root-derived OM but also of stabilized OM that is commonly not attracting microorganisms in the absence of fresh root-derived OM (Fontaine et al., 2007). Likely, priming led to the net loss of $\mathrm{C}$ over long time spans of several millennia at a southwestern German loess-paleosol sequence containing ancient calcified roots (Gocke et al., 2014b). At the site of the current study, $\mathrm{C}$ within the PA and rEP might not be stabilized very well due to low clay, high sand and at the same time low Fe contents, thus facilitating these large $\mathrm{C}$ stocks to mineralization by microorganisms associated with the recent tree vegetation that penetrates the profile until $>1.5 \mathrm{~m}$ depth. Likely, C loss is still low after solely 200 years of oak growth and could still be counteracted by introduction of high amounts of root-derived OM but might increase in the future.

Although root distribution patterns and distribution of elemental composition within the investigated profile point to a strong root-derived overprint of the buried soils and OM therein, the difficulty of general conclusions and extrapolation of the results is related to the fact that quantitative assessment of root effects remains difficult. Molecular and isotope analyses together with modeling approaches, which are not targeted in the current study, might substantially improve the conclusions based on the currently available data. Nevertheless, the strong enrichment of roots together with the heterogeneity of the spatial root distribution demands for quantitative assessment of root abundances in paleopedological studies that are based on chemical properties. Otherwise, the obtained data are likely prone to misinterpretations due to root penetration and related modification of geochemical proxies as only recently highlighted (Gocke et al., 2014b).

\section{Conclusions}

The current multi-proxy approach added by pseudo-threedimensional investigation of root abundances in the soilsediment profile $\mathrm{R}_{2014}$ in southeastern Netherlands points to the significance of roots in pedogenic processes and paleoenvironmental assessment of buried soils. The soil profile developed in sandy parent material and clearly showed that recent oak roots may exploit the deep subsoil $\gg 0.5 \mathrm{~m}$ for nutrients, with a thick buried nutrient-rich plaggic horizon providing beneficial growth conditions. Consequently, high root frequencies are not necessarily a typical feature of topsoils, but roots can maximize in deep subsoils, if plants are forced to produce highly abundant fine roots due to stress, e.g., by Al toxicity or consolidated subsoil horizons. Individual phases of soil formation thus overlap in the investigated profile. This does not necessarily affect the pollen record traditionally studied in such archives but can entail uncertainties for geochemical investigations such as elemental distribution patterns or molecular and/or isotopic approaches that are used to decipher, e.g., different sources of OM in paleosols. The current study strongly suggests that root quantities and their lateral and depth distribution should be assessed as detailed as possible and not solely at the profile wall, where especially fine roots might be strongly underestimated. Although the outcome of the current study clearly points to weaknesses of some widely used approaches for pedogenic and paleoenvironmental assessments in the terrestrial realm, we are aware that general conclusions drawn from a single profile have to be supported by additional soil profiles on the one hand and molecular data on the other hand, which are scheduled in further investigations.

\section{Data availability}

The underlying research data can be accessed publicly via the Supplement.

\section{The Supplement related to this article is available online at doi:10.5194/soil-2-537-2016-supplement.}

Author contributions. M. I. Gocke and G. L. B. Wiesenberg initiated the study. J. van Mourik and B. Jansen gave an introduction to the study site and available literature. G. L. B. Wiesenberg, F. Kessler and M. I. Gocke conducted field work and sampling. Laboratory analysis and data compilation were done by F. Kessler during his master thesis under supervision by M. I. Gocke and G. L. B. Wiesenberg. M. I. Gocke and G. L. B. Wiesenberg prepared the first draft of the manuscript with contributions from all co-authors. 
Acknowledgements. Funding of this study by the Swiss National Science Foundation (SNSF) is greatly acknowledged. S. Abiven (University of Zurich) provided $\mathrm{C}_{\text {org }}$ measurement, while S. Roethlisberger (University of Zurich) introduced F. Kessler to the respective other laboratory analytical methods. The authors thank the city of Uden for giving permission to prepare a soil pit and to collect samples at Bedafse Bergen.

Edited by: S. Kluiving

Reviewed by: two anonymous referees

\section{References}

Anderson, H. A., Berrow, M. L., Farmer, V. C., Hepburn, A., Russell, J. D., and Walker, A. D.: A reassessment of podzol formation processes, J. Soil Sci. 33, 125-136, 1982.

Andreeva, D. B., Zech, M., Glaser, B., Erbajeva, M. A., Chimitdorgieva, G. D., Ermakova, O. D., and Zech, W.: Stable isotope $\left(\delta^{13} \mathrm{C}, \delta^{15} \mathrm{~N}, \delta^{18} \mathrm{O}\right)$ record of soils in Buryatia, southern Siberia: Implications for biogeochemical and paleoclimatic interpretations, Quaternary Int., 290-291, 82-94, 2013.

Baritz, R., Seufert, G., Montanarella, L., and van Ranst, E.: Carbon concentrations and stocks in forest soils of Europe, Forest Ecol. Manag., 260, 262-277, 2010.

Blume, H.-P. and Leinweber, P.: Plaggen soils: landscape history, properties, and classification, J. Plant Nutr. Soil Sc., 167, 319327, 2004.

Bockheim, J.: Distribution and Genesis of Ortstein and Placic Horizons in Soils of the USA: A Review, Soil Sci. Soc. Am. J., 75, 994-1005, 2011.

Buggle, B., Wiesenberg, G. L. B., and Glaser, B.: Is there a possibility to correct fossil $n$-alkane data for postsedimentary alteration effects?, Appl. Geochem., 25, 947-957, 2010.

Canadell, J., Jackson, R. B., Ehleringer, J. R., Mooney, H. A., Sala, O. E., and Schulze, E. D.: Maximum rooting depth of vegetation types at the global scale, Oecologia, 108, 583-595, 1996.

Commission Internationale de l'Eclairage (CIE): Proceedings of the 8th session of CIE, Cambridge University Press, UK, 1931.

Coutts, M. P., Nielsen C. C. N., and Nicoll, B. C.: The development of symmetry, rigidity and anchorage in the structural root system of conifers, Plant Soil, 217, 1-15, 1999.

Driessen, P. M. and Dudal, R.: The Major Soils of the World, Koninklijke Wöhrmann B. V., Zutphen, The Netherlands, 1991.

Eckelmann, W.: Plaggenesche aus Sanden, Schluffen und Lehmen sowie Oberflächenveränderungen als Folge der Plaggenwirtschaft in den Landschaften des Landkreises Osnabrück, Geologisches Jahrbuch, 10, 1-95, 1980.

Egli, M., Gristina, L., Wiesenberg, G. L. B., Civantos, J. M. M., Rotolo, A., Novara, A., Brandovà, D., and Raimondi, S.: From pedologic indications to archaeological reconstruction: deciphering land use in the Islamic period in the Baida district (northwestern Sicily), J. Archaeol. Sci., 40, 2670-2685, 2013.

FAO: Guidelines for soil description, 4th Edn., Rome, 2006.

Fontaine, S., Barot, S., Barré, P., Bdioui, N., Mary, B., and Rumpel, C.: Stability of organic carbon in deep soil layers controlled by fresh carbon supply, Nature, 450, 277-281, 2007.

Giani, L., Makowsky, L., and Mueller, K.: Plaggic Anthrosol: Soil of the Year 2013 in Germany. An overview on its formation, dis- tribution, classification, soil function and Threats, J. Plant Nutr. Soil Sc., 177, 320-329, 2014.

Gocke, M., Hambach, U., Eckmeier, E., Schwark, L., Zöller, L., Fuchs, M., Löscher, M., and Wiesenberg, G. L. B.: Introducing an improved multi-proxy approach for paleoenvironmental reconstruction of loess-paleosol archives applied on the Late Pleistocene Nussloch sequence (SW Germany), Palaeogeogr. Palaeocl., 410, 300-315, 2014a.

Gocke, M., Peth, S., and Wiesenberg, G. L. B.: Lateral and depth variation of loess organic matter overprint related to rhizoliths - Revealed by lipid molecular proxies and X-ray tomography, Catena, 112, 72-85, 2014b.

Harper, R. J. and Tibbett, M.: The hidden organic carbon in deep mineral soils, Plant Soil, 368, 641-648, 2013.

Harrison, R. B., Footen, P. W., and Strahm, B. D.: Deep soil horizons: Contributions and importance to soil carbon pools and in assessing whole-ecosystem response to management and global change, Forest Sci., 57, 67-76, 2011.

Hillel, D.: Fundamentals of Soil Physics, Academic Press, Inc., New York, 1980.

Hodge, A., Berta, G., Doussan, C., Merchan, F., and Crespi, M.: Plant root growth, architecture and function, Plant Soil, 321, 153-187, 2009.

Huguet, A., Wiesenberg, G. L. B., Gocke, M., Fosse, C., and Derenne, S.: Branched tetraether membrane lipids associated with rhizoliths in loess: Rhizomicrobial overprinting of initial biomarker record, Org. Geochem., 43, 12-19, 2012.

IUSS Working Group WRB: World Reference Base for Soil Resources 2014, World Soil Resources Reports No. 106 FAO, Rome, Italy, 2014.

Jansen, B., van Loon, E. E., Hooghiemstra, H., and Verstraten, J. M.: Improved reconstruction of palaeo-environments through unravelling of preserved vegetation biomarker patterns. Palaeogeogr. Palaeocl., 285, 119-130, 2010.

Jobbàgy, E. G. and Jackson, R. B.: The Vertical Distribution of Soil Organic Carbon and Its Relation to Climate and Vegetation, Ecol. Appl., 10, 423-436, 2000.

Jobbàgy, E. G. and Jackson, R. B.: The distribution of soils nutrients with depth: Gobal patterns and the imprint of plants, Biogeochemistry, 53, 51-77, 2001.

Johnson, W. C.: Sequestration in buried soils, Nat. Geosci., 7, 398 399, 2014.

Kautz, T., Amelung, W., Ewert, F., Gaiser, T., Horn, R., Jahn, R., Javaux, M., Kemna, A., Kuzyakov, Y., Munch, J.-C., Pätzold, S., Peth, S., Scherer, H. W., Schloter, M., Schneider, H., Vanderborght, J., Vetterlein, D., Walter, A., Wiesenberg, G. L. B., and Köpke, U.: Nutrient acquisition from arable subsoils in temperate climates: A review, Soil Biol. Biochem., 57, 1003-1022, 2013.

Kell, D. B.: Large-scale sequestration of atmospheric carbon via plant roots in natural and agricultural ecosystems: why and how, Philos. T. Roy. Soc. B, 367, 1589-1597, 2012.

Konen, M. E., Burras, C. L., and Sandor, J. A.: Organic carbon, texture, and quantitative color measurement relationships for cultivated soils in North Central Iowa, Soil Sci. Soc. Am. J., 67, 1823-1830, 2003.

Lal, R.: Tillage effects on soil degradation, soil resilience, soil quality, and sustainability, Soil Till. Res., 27, 1-8, 1994.

Li, Z., Wang, N., Li, R., Ning, K., Cheng, H., and Zhao, L.: Indication of millennial-scale moisture changes by the temporal dis- 
tribution of Holocene calcareous root tubes in the deserts of the Alashan Plateau, Northwest China, Palaeogeogr. Palaeocl., 440, 496-505, 2015.

Lorenz, K., Lal, R., and Shipitalo, M. J.: Stabilized soil organic carbon pools in subsoils under forest are potential sinks for atmospheric $\mathrm{CO}_{2}$, Forest Sci., 57, 19-25, 2011.

Maeght, J. L., Rewald, B., and Pierret, A.: How to study deep roots - and why it matters, Frontiers in Plant Science, 4, 299, doi:10.3389/fpls.2013.00299, 2013.

Marin-Spiotta, E., Chaopricha, N. T., Plante, A. F., Diefendorf, A. F., Mueller, C. W., Grandy, A. S., and Mason, J. A.: Long-term stabilization of deep soil carbon by fire and burial during early Holocene climate change, Nat. Geosci., 7, 428-432, 2014.

Mendez-Millan, M., Nguyen Tu, T. T., Balesdent, J., Derenne, S., Derrien, D., Egasse, C., Thongo M'Bou, A., Zeller, B., and Hatté, C.: Compound-specific ${ }^{13} \mathrm{C}$ and ${ }^{14} \mathrm{C}$ measurements improve the understanding of soil organic matter dynamics, Biogeochemistry, 118, 205-223, 2014.

Millikin, C. S. and Bledsoe, C. S.: Biomass and distribution of fine and coarse roots from blue oak (Quercus douglasii) trees in the northern Sierra Nevada foothills of California, Plant Soil, 214, 27-38, 1999.

Moreno, G., Obrador, J. J., Cubera, E., and Dupraz, C.: Fine Root Distribution in Dehesas of Central-Western Spain, Plant Soil, 277, 153-162, 2005.

Müller, H.-W., Dohrmann, R., Klosa, D., Rehder, S., and Eckelmann, W.: Comparison of two procedures for particle-size analysis: Köhn pipette and X-ray granulometry, J. Plant Nutr. Soil Sc., 172, 172-179, 2009.

PAGES 2k Consortium: Continental-scale temperature variability during the past two millennia, Nat. Geosci., 6, 339-346, 2013.

Pape, J. C.: Plaggen soils in the Netherlands, Geoderma, 4, 229255, 1970

Perkons, U., Kautz, T., Uteau, D., Peth, S., Geier, V., Thomas, K., Lütke Holz, K., Athmann, M., Pude, R., and Köpke, U.: Rootlength densities of various annual crops following crops with contrasting root systems, Soil Till. Res., 137, 50-57, 2014.

Poschenrieder, C., Gunse, B., Corrales, I., and Barcelo, J.: A glance into aluminum toxicity and resistance in plants, Sci. Total Environ., 400, 356-368, 2008.

Pye, K. and Sherwin, D.: Loess, chap. 10, in: Aeolian Environments, Sediments and Landforms, edited by: Goudie, A. S., Livingstone, I., and Stokes, S., Wiley, Chichester, 213-238, 1999.

Rasse, D. P., Rumpel, C., and Dignac, M.-F.: Is soil carbon mostly root carbon? Mechanisms for a specific stabilisation, Plant Soil, 269, 341-356, 2005.

Richter, D. D. and Markewitz, D.: How deep is soil?, BioScience, 45, 600-609, 1995.

Ryan, P. R., Shaff, J. E., and Kochian, L. V.: Aluminum Toxicity in Roots: Correlation among Ionic Currents, Ion Fluxes, and Root Elongation in Aluminum-Sensitive and AluminumTolerant Wheat Cultivars, Plant Physiol., 99, 1193-1200, 1992.

Sachse, D., Kahmen, A., and Gleixner, G.: Significant seasonal variation in the hydrogen isotopic composition of leaf-wax lipids for two deciduous tree ecosystems (Fagus sylvativa and Acer pseudoplatanus), Org. Geochem., 40, 732-742, 2009.

Sainju, U. M. and Good, R. E.: Vertical root distribution in relation to soil properties in New Jersey Pinelands forests, Plant Soil, 150, 87-97, 1993.
Sauer, D., Sponagel, H., Sommer, M., Giane, L., Jahn, R., and Stahr, K.: Podzol: Soil of the Year 2007. A review on its genesis, occurrence, and functions, J. Plant Nutr. Soil Sc., 170, 581-597, 2007.

Schmidt, M. W. I., Torn, M. S., Abiven, S., Dittmar, T., Guggenberger, G., Janssens, I. A., Kleber, M., Kögel-Knabner, I., Lehmann, J., Manning, D. A. C., Nannipieri, P., Rasse, D. P., Weiner, S., and Trumbore, S. E.: Persistence of soil organic matter as an ecosystem property, Nature, 478, 49-56, 2011.

Schulze, D. G., Nagel, J. L., van Scoyoc, G. E., Henderson, T. L., Baumgardner, M. F., and Stott, D. E.: Significance of soil organic matter in determining soil colors, in: Soil Color, edited by: Bigham, J. M. and Ciolkosz, E. J., SSSA Special Publication 31. ASA, CSSA, SSSA, Madison, WI, 71-90, 1993.

Thomas, F.: Vertical rooting patterns of mature Quercus trees growing on different soil types in northern Germany, Plant Ecol., 147, 95-103, 2000.

Újvári, G., Molnár, M., Novothny, Á., Páll-Gergeley, B., Kovács, J., and Várhegyi, A.: AMS ${ }^{14} \mathrm{C}$ and OSL/IRSL dating of the Dunaszekcso loess sequence (Hungary): chronology for 20 to $150 \mathrm{ka}$ and implications for establishing reliable age-depth models for the last $40 \mathrm{ka}$, Quaternary Sci. Rev., 106, 140-154, 2014.

Van Mourik, J. M. and Jansen, B.: The added value of biomarker analysis in palaeopedology; reconstruction of the vegetation during stable periods in a polycyclic driftsand sequence in SENetherlands, Quaternary Int., 306, 14-23, 2013.

Van Mourik, J. M., Nierop, K. G. J., and Vandenberghe, D. A. G.: Radiocarbon and optically stimulated luminescence dating based chronology of a polycyclic driftsand sequence at Weerterbergen (SE Netherlands), Catena, 80, 170-181, 2010.

Van Mourik, J. M., Seijmonsbergen, A. C., Slotboom, R. T., and Wallinga, J.: Impact of human land use on soils and landforms in cultural landscapes on aeolian sandy substrates (Maashorst, SE-Netherlands), Quaternary Int., 265, 74-89, 2012.

Van Mourik, J. M., Wagner, T. V., de Boer, J. G., and Jansen, B.: The added value of biomarker analysis to the genesis of plaggic Anthrosols; the identification of stable fillings used for the production of plaggic manure, SOIL, 2, 299-310, doi:10.5194/soil2-299-2016, 2016.

Wallinga, J., van Mourik, J. M., and Schilder, M. L. M.: Identifying and dating buried micropodzols in Subatlantic polycyclic drift sands, Quaternary Int., 306, 60-70, 2013.

Wells, P. S.: The Battle that Stopped Rome: Emperor Augustus, Arminius, and the Slaughter of the Legions in the Teutoburg Forest, W. W. Norton and Company, London, UK, 2004.

Wiesenberg, G. L. B., Schwark, L., and Schmidt, M. W. I.: Extractable lipid contents and colour in particle-size separates and bulk arable soils, Eur. J. Soil Sci., 57, 634-643, 2006.

Wiesenberg, G. L. B., Andreeva, D. B., Chimitdorgieva, G. D., Erbajeva, M. A., and Zech, W.: Reconstruction of environmental changes during the late glacial and Holocene reflected in a soilsedimentary sequence from the lower Selenga River valley, Lake Baikal region, Siberia, assessed by lipid molecular proxies, Quaternary Int., 365, 190-202, 2015.

Wiesmeier, M., Spörlein, P., Geu, U., Hangen, E., Haug, S., Reischl, A., Schilling, B., von Lützow, M., and Kögel-Knabner, I.: Soil organic carbon stocks in southeast Germany (Bavaria) as affected by land use, soil type and sampling depth, Glob. Change Biol., 18, 2233-2245, 2012. 